\title{
Temperature sensitivity of mineral soil carbon decomposition in shrub and graminoid tundra, west Greenland
}

\author{
Julia I. Bradley-Cook ${ }^{1 *}$, Chelsea L. Petrenko ${ }^{1}$, Andrew J. Friedland ${ }^{2}$ and Ross A. Virginia ${ }^{3}$
}

\begin{abstract}
Background: Shrub expansion is transforming Arctic tundra landscapes, but the impact on the large pool of carbon stored in high-latitude soils is poorly understood. Soil carbon decomposition is a potentially important source of greenhouse gases, which could create a positive feedback to atmospheric temperature. Decomposition is temperature sensitive, but the response to temperature can be altered by environmental variables. We focus on mineral soils, which can comprise a substantial part of the near-surface carbon stock at the landscape scale and have physiochemical characteristics that influence temperature sensitivity. We conducted a soil incubation experiment to measure carbon dioxide $\left(\mathrm{CO}_{2}\right)$ emissions from tundra soils collected from west Greenland at two depths of mineral soils $(0-20 \mathrm{~cm}$ and $20-40 \mathrm{~cm}$ below the surface organic horizon) incubated at five temperatures $\left(4,8,12,16,24^{\circ} \mathrm{C}\right)$ and two moisture levels ( $40 \%$ and $60 \%$ water holding capacity). We used an information theoretic model comparison approach to evaluate temperature, moisture and depth effects, and associated interactions, on carbon losses through respiration and to determine the temperature sensitivity of decomposition in shrub- and graminoid-dominated soils.
\end{abstract}

Results: We measured ecologically important differences in heterotrophic respiration and temperature sensitivity of decomposition between vegetation types. Graminoid soils had 1.8 times higher cumulative respiration and higher temperature sensitivity (expressed as Q-10) in the shallow depths $\left(\mathrm{Q}-10_{\text {graminoid }}=2.3, \mathrm{Q}-10_{\text {shrub }}=1.8\right.$ ) compared to shrub soils. Higher Q-10 in graminoid soils was also observed for the initial incubation measurements $\left(\mathrm{Q}-10_{\text {graminoid }}=2.4, \mathrm{Q}-10_{\text {shrub }}=1.9\right)$. Cumulative respiration was also higher for shallow soils, increased with moisture level, and had a temperature-depth interaction. Increasing soil moisture had a positive effect on temperature sensitivity in graminoid soils, but not in shrub soils.

Conclusion: Mineral soil associated with graminoid-dominated vegetation had greater carbon losses from decomposition and a higher temperature sensitivity than shrub-dominated soils. An extrapolation of our incubation study suggests that organic carbon decomposition in western Greenland soils will likely increase with warming and with an increase in soil moisture content. Our results indicate that landscape level changes in vegetation and soil heterogeneity are important for understanding climate feedbacks between tundra and the atmosphere.

\footnotetext{
* Correspondence: Julia.I.Bradley-Cook.GR@Dartmouth.edu

'Department of Biological Sciences, Dartmouth College, Hanover NH 03755, USA

Full list of author information is available at the end of the article
} 


\section{Background}

Shrub expansion is occurring across Arctic tundra ecosystems $[1,2]$ and is contributing to above and belowground carbon feedbacks to climate through impacts on greenhouse gas exchange and surface energy balance between the terrestrial environment and atmosphere [3]. While it is well established that an increase in shrub extent and abundance increases aboveground biomass, it is likely that these shifts will also affect the large pools of belowground carbon stored in tundra and permafrost soils [4]. Arctic soils are a particularly important carbon pool because they contain half of global soil carbon and more than two times the amount of carbon as the atmosphere $[5,6]$. The magnitude of this carbon pool and its theoretical sensitivity to increasing temperature creates the potential for a positive feedback to global climate change via the release of greenhouse gases from organic matter decomposition [7, 8]. This soil carbon feedback has the potential to transform the arctic terrestrial ecosystem from a carbon sink to a carbon source $[9,10]$.

Vegetation impacts belowground carbon processes through a variety of plant-soil interactions. Plants introduce carbon into the soil through litter fall, fine root turnover and root exudation. The species and functional type of vegetation can influence the quantity and quality of carbon transferred to soils [11-13]. For instance, woody plants produce biomass with high lignin concentration, so woody litter tends to have high $\mathrm{C}: \mathrm{N}$ ratios relative to herbaceous species, which results in a lower quality resource for soil microbial communities $[14,15]$. C:N ratios of plant derived materials is a measure of carbon substrate quality and have been negatively correlated with organic matter decomposition in the Arctic [16-18]. Rooting depth affects the vertical distribution of soil carbon [19] because root exudation and turnover directly introduce carbon into soils [20, 21] and can stimulate microbial decomposition and nutrient mobilization through "priming" communities with labile carbon [21, 22]. Lastly, vegetation alters belowground environmental conditions, such as soil temperature and moisture, which influence decomposition rates through thermodynamic and water resource control on microbial metabolism [12, 23].

Temperature is a key determinant of carbon mineralization and the balance of arctic soil carbon in a changing environment. The relationship between microbial respiration and temperature, or temperature sensitivity, is represented in many global carbon models by Q-10, which measures the change in respiration rate as a result of a $10{ }^{\circ} \mathrm{C}$ increase in temperature. Thermodynamic theory predicts that low quality, chemically recalcitrant, carbon is less decomposable and has higher temperature sensitivity than high quality, labile carbon [24]. While many studies support this fundamental understanding of carbon mineralization, some findings contrast with the predictions, showing no change or a decrease in temperature sensitivity with increasing soil carbon recalcitrance $[25,26]$. The Carbon-Quality Temperature hypothesis posits that the relationship between quality and temperature sensitivity can be moderated by environmental constraints, such as frozen temperatures, anoxic conditions, or physical protection of carbon molecules $[27,28]$. Empirical studies show a range of relationships between temperature sensitivity and carbon quality. Therefore, temperature sensitivity models that do not represent environmental constraints often fail to predict observed temperature sensitivity from incubation experiments.

Improving predictions of the response of soil carbon pools to warming requires understanding the complex controls on soil organic carbon mobilization, including interactions between simultaneous drivers of change (e.g. climate change, shifts in biological communities) [29]. We have a limited understanding of the integrated effect of shrub expansion and warming atmospheric temperatures on soil carbon processes, and few studies have investigated these dynamics in mineral tundra soils. Mineral soils have lower carbon concentrations, but constitute a large portion of the total soil carbon pool in soils with minimal organic horizon development, such as polar desert or upland soils [30-32]. Furthermore, these soils allow us to investigate the role of physical protection of carbon (through adsorption to mineral surfaces or aggregation) on temperature sensitivity of decomposition [33, 34].

The objective of this study was to investigate the interactive effects of temperature and moisture on soil decomposition in an Arctic landscape with heterogeneous vegetation. We investigated four possible biotic and abiotic controls, along with their interactive relationships, on decomposition rates and the temperature sensitivity of decomposition in mineral soils: (1) vegetation cover, (2) soil depth, (3) temperature, and (4) soil moisture.

To address our objective, we conducted a 49-day laboratory incubation experiment on soils collected from western Greenland. We measured respiration from mineral soils at two depth increments within the active layer (0-20 cm and 20-40 cm below the organic layer) collected from graminoid-dominated (Poa pratensis) and shrub-dominated (Betula nana and Salix glauca) vegetation, in a fully crossed laboratory experiment with multiple temperature and moisture treatment levels. Because graminoid soils have larger organic carbon pools and lower C:N ratios than shrub soils [35], we hypothesized that: (1) graminoid soils would have higher rates of decomposition and lower temperature sensitivity than shrubs as a result of a larger soil carbon pool and higher soil carbon quality, as measured by $\mathrm{C}: \mathrm{N}$; (2) deep soils 
would have lower decomposition rates and higher temperature sensitivity compared to near-surface soils due to a smaller and lower quality soil carbon pool; (3) higher temperatures would increase decomposition rates, but would also decrease temperature sensitivity in accordance with amplified responses of polar biological processes at low temperatures [36]; and (4) a soil moisture increase reflecting the 30-40\% increase in regional precipitation projected by the years 20512080 [37] would result in higher decomposition rates and temperature sensitivity because semi-arid tundra soils are typically water-limited.

\section{Results}

\section{Field environmental conditions}

Mean air temperature at the study site from midsummer 2011 to mid-summer 2012 was $-5.6{ }^{\circ} \mathrm{C}$. Mean growing season temperature was $10.9{ }^{\circ} \mathrm{C}$, with a maximum recorded temperature of $21.5{ }^{\circ} \mathrm{C}$. Annual soil temperatures were comparable between graminoid and shrub-dominated vegetation (Table 1). Growing season soil temperatures were $0.6{ }^{\circ} \mathrm{C}$ higher in shrub soils than graminoid soils. Gravimetric soil water content at the time of collection was higher in graminoid soils than shrub soils (mean \pm 1 s.e., $\mathrm{g} \mathrm{H}_{2} \mathrm{O}{ }^{*} \mathrm{~g} \mathrm{Soil}^{-1}$ : graminoid $=0.41 \pm 0.03$, shrub $=0.27 \pm 0.02 ; \Delta$ AICc $=9.6$ ). Water holding capacity (WHC) was also higher in graminoid soils (mean \pm 1 s.e., g $\mathrm{H}_{2} \mathrm{O} * \mathrm{~g} \mathrm{Soil}^{-1}$ : graminoid $=$ $0.89 \pm 0.08$, shrub $=0.64 \pm 0.05 ; \triangle \mathrm{AICc}=4.3$ ), so the percent water holding capacity (\% WHC) of field moist samples did not significantly differ between vegetation types ( mean \pm 1 s.e., \%: graminoid $=47.6 \pm 3.1$, shrub $=42.1 \pm$ 2.2; $\triangle \mathrm{AICc}=0.1$ ).

Vegetation at the five graminoid sample locations contained $100 \%$ graminoid cover (dominated by Poa pretensis), and the five shrub sample locations contained an average of $96 \%$ Betula nana coverage. Canopy height of graminoid vegetation was lower than the shrub canopy (mean \pm 1 s.e., cm: $14.2 \pm 1.0$ and $20.4 \pm 0.5$, respectively; $t=5.7, \mathrm{P}<0.01$, d.f. $=8$ ).

\section{Soil organic matter concentration}

Organic matter concentrations were higher in graminoid soils. In shallow soils, which were the top $20 \mathrm{~cm}$ of mineral soil, graminoid soil had higher mean organic matter concentration than shrub soil (Table $2 ; t=1.85, \mathrm{P}=0.05$, d.f. $=8$ ). In deep soils, the $20-40 \mathrm{~cm}$ depth increment, mean graminoid soil organic matter concentration was significantly higher than that of shrub soils (Table 2; $t=$ $1.98, \mathrm{P}<0.05$, d.f. $=7$ ). These results correspond with a soil carbon concentration analysis conducted by Petrenko et al. [35], which shows significantly larger carbon pools in graminoid soils (Table 2).

\section{$\mathrm{CO}_{2}$ production and cumulative respiration}

Shallow soils had a wider range of $\mathrm{CO}_{2}$ production rates than deep soils and a steeper decline in $\mathrm{CO}_{2}$ production rate over the duration of the incubation (Fig. 1). Within each treatment combination, the mean soil respiration of day 1 measurements was 1.4 to 3.4 times greater for graminoid soils than shrub soils (Fig. 1). The response of soil respiration over the course of the 49-day incubation differed between shallow and deep soils (Fig. 1). Shallow soils had steeper decline in decay rate than deep soils (mean $k \pm$ 1 s.e.: shallow $=-0.071 \pm 0.006$ and deep $=-0.015 \pm 0.001$ ). Carbon dioxide production increased with temperature for both vegetation types and soil depths (Fig. 1).

We hypothesized that vegetation type, depth, temperature, and moisture would control cumulative respiration. The model comparison identified all of these variables as main effects on cumulative respiration, along with a temperature-depth interaction term (Table 3). The model with these basic parameters explained $94 \%$ of the variance in the data $\left(\mathrm{F}_{6,173}=493.3, \mathrm{P}<0.01\right)$. Additional interaction terms, temperature-vegetation and depth-vegetation, appeared in the set of best fitting models, but these terms were "pretending variables" that did not increase the likelihood of the model fit enough to prioritize these models [38]. We focused our analysis on the most parsimonious model without the "pretending" interaction terms.

Table 1 Mean air and soil temperatures at the study site. Soil temperatures were recorded for graminoid and shrub vegetation types

\begin{tabular}{|c|c|c|c|c|c|c|}
\hline & \multicolumn{2}{|c|}{ Air Temp $\left({ }^{\circ} \mathrm{C}\right)$} & \multicolumn{4}{|l|}{ Soil Temperature $\left({ }^{\circ} \mathrm{C}\right)$} \\
\hline & $\overline{\text { Annual }^{a}}$ & Growing Season $^{b}$ & Annual Graminoid $^{c}(n=2)$ & Annual Shrub ${ }^{c}(n=1)$ & GS Graminoid $^{d}(n=2)$ & $\operatorname{GS~Shrub~}^{d}(n=1)$ \\
\hline Mean & -5.6 & 10.9 & -2.9 & -2.9 & 4.3 & 3.7 \\
\hline Max & 21.5 & 21.5 & 10.0 & 9.5 & 10.0 & 9.5 \\
\hline Min & -40 & -5.5 & -16.0 & -14.0 & 0.0 & 0.0 \\
\hline
\end{tabular}

Time interval of the data record is indicated for each column

${ }^{a}$ Annual air temperature dates: 7/21/11 - 7/20/12

${ }^{b}$ Growing season air temperature dates: 7/21/11 - 8/7/11 and 5/22/12 - 7/20/12

'Annual soil temperature dates: $7 / 21 / 11-6 / 26 / 12$

${ }^{d}$ Growing season soil temperature dates: $7 / 21 / 11-8 / 7 / 11$ and 5/22/12 - 6/26/12 
Table 2 Organic matter content and C:N ratios by vegetation type and depth

\begin{tabular}{lllll}
\hline & Depth & Increment & Graminoid & Shrub \\
\hline Organic Matter (\%) & Shallow & $0-20 \mathrm{~cm}$ & $12.8 \pm 0.4$ & $10.0 \pm 1.5$ \\
& Deep & $20-40 \mathrm{~cm}$ & $10.9 \pm 0.7$ & $8.1 \pm 1.3$ \\
C:N & Shallow & $0-20 \mathrm{~cm}$ & 14.14 & 15.74 \\
& Deep & $20-40 \mathrm{~cm}$ & 15.27 & 16.68 \\
Soil C pool* $\left(\mathrm{kg} \mathrm{C} \mathrm{m}^{-2}\right)$ & - & - & 29.0 & 22.5 \\
\hline
\end{tabular}

Values are mean \pm 1 standard error

*Source: Petrenko et al., in review

Temperature, vegetation cover, depth, and moisture were all important controls on cumulative respiration (Fig. 2, Table 4, Additional file 1: Figure S1). Temperature had a strong, positive effect on cumulative respiration (Table 4). Mean cumulative respiration, as applied to a combined analysis for all soil samples across vegetation and depths, increased from $53.4 \pm 8.2 \mathrm{mg} \mathrm{CO}_{2}-\mathrm{C} \mathrm{gOM}^{-1}$ at $4{ }^{\circ} \mathrm{C}$ to
$240.8 \pm 50.6 \mathrm{mg} \mathrm{CO}_{2}-\mathrm{C} \mathrm{gOM}^{-1}$ at $24{ }^{\circ} \mathrm{C}$. The data supported the hypothesis that graminoid soils would have significantly higher respiration than shrub soils (Table 4). On average, cumulative respiration was $43 \%$ lower in shrub soils than graminoid soils (Table 4). The high moisture treatment significantly increased cumulative soil respiration by $15 \%$ (Table 4 ). In addition to the main effects, the effect of temperature on cumulative respiration interacted with depth: with increasing temperature, cumulative respiration increased more rapidly for deep soil than shallow soil (Table 4). Shallow soil had 10.1 times higher mean cumulative respiration than deep soil (mg $\mathrm{CO}_{2}-\mathrm{C} \mathrm{gOM}^{-1}$ : shallow $=169.4$ and deep $=16.8$ ).

\section{Temperature sensitivity of cumulative respiration}

The average Q-10 of cumulative respiration ranged from 1.7 to 2.9 for shallow soils, and from 2.1 to 3.1 for deep soils (Fig. 3, Additional file 2: Figure S2). In the prediction of cumulative respiration temperature

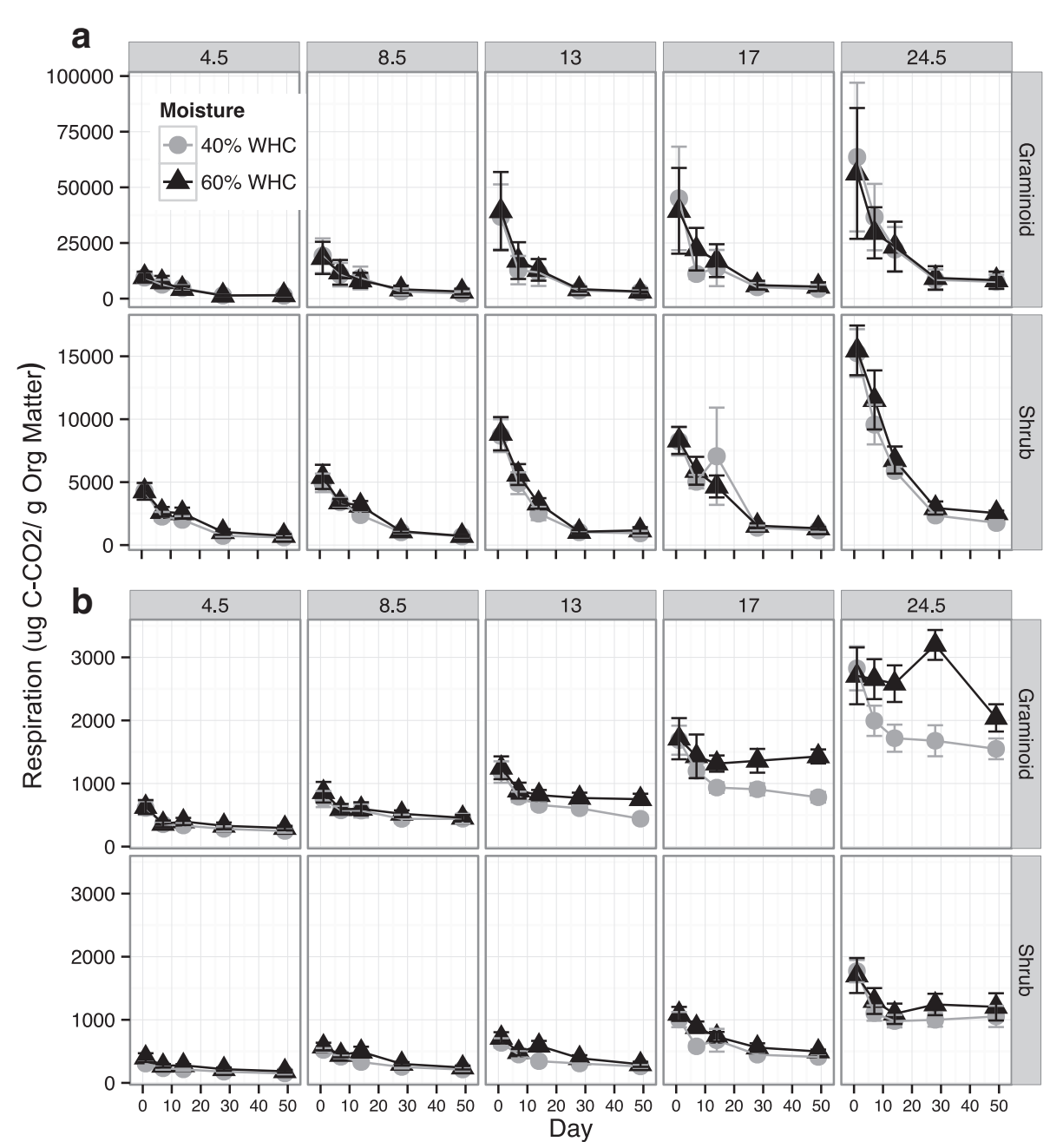

Fig. 1 Mean respiration over the incubation period for a shallow and $\mathbf{b}$ deep soils. Each panel corresponds to a temperature treatment $\left({ }^{\circ} \mathrm{C}\right)$ and soil type (graminoid and shrub). Low moisture (40\% WHC) soils are indicated by gray circles, and high moisture (60\% WHC) by black triangles 
Table 3 Plausible models ( $\triangle \mathrm{AlC}<2$ ) explaining cumulative soil respiration

\begin{tabular}{llllccc}
\hline Model Rank & Predictor Variable & No. of Parameters & AlCc & AAlCc & AlCc Model Weight & Log-likelihood Log (L) \\
\hline 1 & Temp + Moisture + Veg + Depth + Temp:Depth & 7 & 110.9 & 0.0 & 0.30 & -48.13 \\
2 & $\begin{array}{l}\text { Temp + Moisture + Veg + Depth + Temp:Depth } \\
\text { + Temp:Veg }\end{array}$ & 8 & 111.2 & 0.3 & 0.26 & -47.18 \\
3 & $\begin{array}{l}\text { Temp + Veg + Moisture + Depth + Temp:Depth } \\
\text { + Temp:Veg + Depth:Veg }\end{array}$ & 9 & 112.2 & 1.3 & 0.16 & -46.57
\end{tabular}

Models that contain all four main effects (temperature (Temp), vegetation type (Veg), moisture level (Moisture), depth (Depth)), and a temperature-depth interaction (Temp:Depth) are preferred. Temperature-vegetation (Temp:Veg) and depth-vegetation (Depth:Veg) interactions are "pretending variables" that only marginally increase the likelihood that the model represents that data (Log(L)) (Additional file 3: Table S1)

sensitivity, the top ranked model contained vegetation type, depth, moisture, and temperature as main effects, along with moisture-vegetation and vegetationdepth as interaction terms $\left(\mathrm{R}^{2}\right.$ adj. $=0.3394, \mathrm{~F}_{6,137}=$ 13.25, $\mathrm{P}<0.01$; Table 5). This top ranked model was the most complex of the plausible models $(\triangle \mathrm{AICc}<2)$, while the second and third ranked models contained a subset of predictor variables in the top model (Table 5). The fourth ranked model included a three-way interaction between vegetation, depth and temperature, but the model probability indicated weak evidence that it was the best model to describe the data $(\triangle \mathrm{AICc}=2.13, \mathrm{AICc}$ weight $=0.07)$. The top ranked model contained all the predictor variables in the set of plausible models, so we focused on this model but also considered the information provided by the three-way interaction.

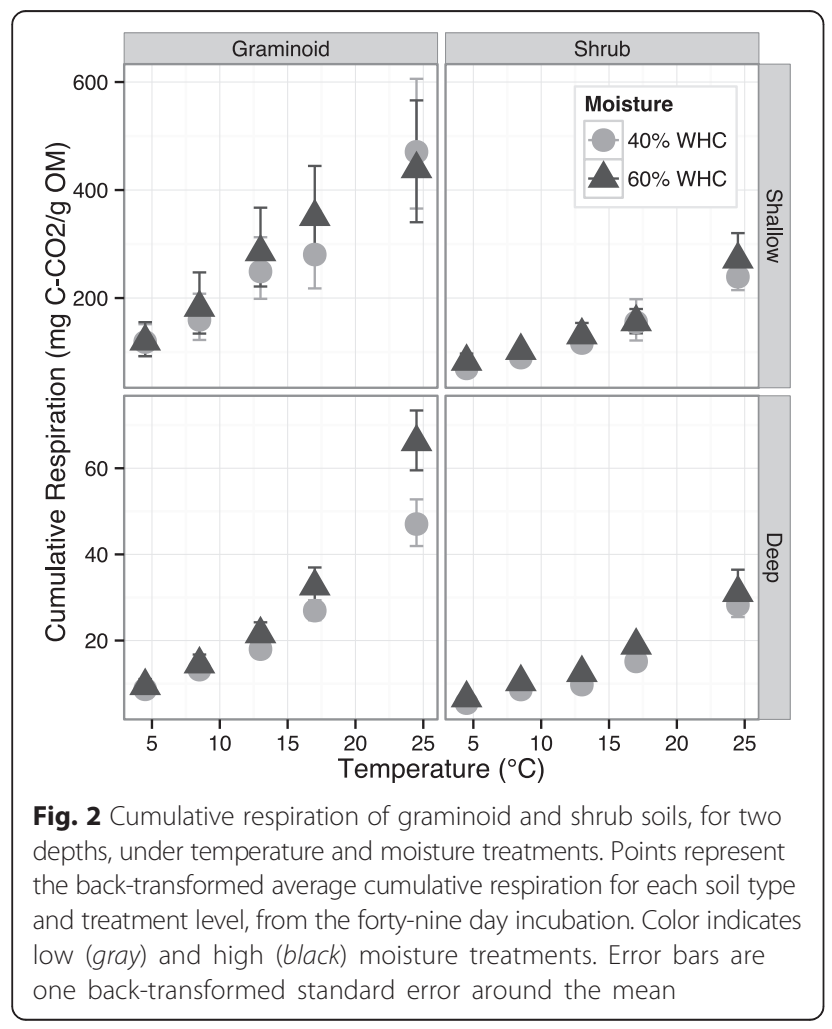

Temperature sensitivity of cumulative respiration decreased with increasing temperature (Table 6). Thus, an increase in soil temperature from 8 to $18{ }^{\circ} \mathrm{C}$ is associated with an average decrease in Q-10 from 2.7 to 2.3. Soil moisture content increased temperature sensitivity in graminoid soils more than shrub soils (Table 6).

The effect of vegetation on cumulative respiration temperature sensitivity differed based on soil depth. Specifically, Q-10 increased with depth in shrub soils more than in graminoid soils (Table 6). At the shallow depth, average Q-10 was 0.5 units higher in graminoid soils than shrub soils (Q-10 mean (mean- 1 s.e., mean +1 s.e.): shallow graminoid $=2.33(2.22,2.44)$, shallow shrub $=$ $1.82(1.75,1.90))$. In the deep soils, however, the difference between the Q-10 of graminoid and shrub soils was less than 0.3 units (Q-10 mean (mean-1 s.e., mean +1 s.e.): deep graminoid $=2.67(2.60,2.74)$, deep shrub $=2.43$ $(2.33,2.52))$. The three-way interaction that appeared in the fourth ranked model captured the same interaction between vegetation and depth, along with the unique temperature response of shallow shrub Q-10 $\left(B_{\text {Temp:Veg(Shrub):Depth(Deep) }}=-0.025 \pm 0.012, P<0.05\right)$. The three-way interaction indicates that cumulative respiration of Q-10 of shallow shrub soils did not change with temperature, while the Q-10 of deep shrub soils and both depths of graminoid soils declined as temperature increased.

The pattern of higher temperature sensitivity of graminoid soils compared to shrub soils at the shallow depth increment was also observed in calculations of Q-10 for

Table 4 Model summary from the top-ranked model of cumulative respiration

\begin{tabular}{lccccl}
\hline Parameter & Estimate & Std Error & $P$-value & $e^{\wedge(B)}$ & $\%$ effect $^{*}$ \\
\hline Intercept & 11.431 & 0.083 & $<0.001$ & 9,2000 & N/A \\
Temp & 0.063 & 0.005 & $<0.001$ & 1.065 & 6.5 \\
Moisture (60\%WHC) & 0.140 & 0.048 & 0.004 & 1.151 & 15.1 \\
Veg (Shrub) & -0.560 & 0.048 & $<0.001$ & 0.569 & -43.1 \\
Depth (Deep) & -2.670 & 0.105 & $<0.001$ & 0.069 & -93.1 \\
Temp : Depth (Deep) & 0.022 & 0.007 & 0.001 & 1.022 & 2.2 \\
\hline
\end{tabular}

Parameter estimates, standard errors, $\mathrm{p}$-values, back-transformed parameter estimates $\left(e^{\wedge}(B)\right)$, and percent effect are reported for each model term $\%$ effect $=100^{*}\left(e^{B}-1\right)$ 


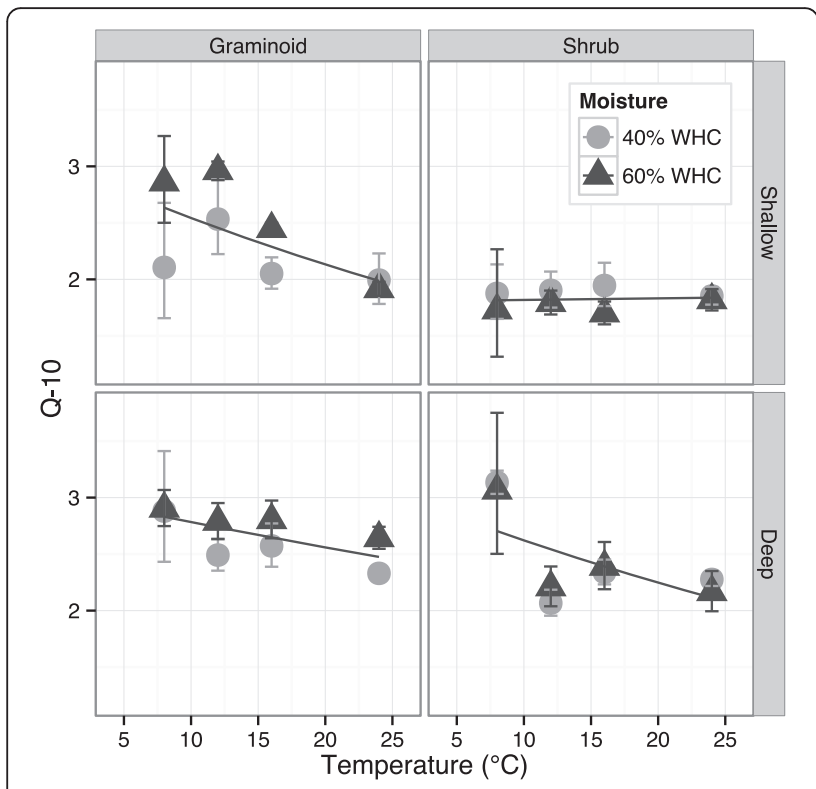

Fig. 3 Temperature sensitivity of cumulative respiration for graminoid and shrub soils from two depths. Data points represent back-transformed means of Q-10 values ( \pm 1 back-transformed s.e.) for the low (gray) and high (black) moisture treatments. The black line represents the model predictions for the top ranked model (Table 5)

respiration rates measured on the first day of the incubation (Fig. 4). The top ranked model to predict day 1 respiration temperature sensitivity contained vegetation type, depth, and temperature as main effects, along with depthtemperature, vegetation-depth, temperature-vegetation as two-way interaction terms, and a three way interaction between vegetation type-depth-temperature $\left(\mathrm{R}^{2}\right.$ adj. $=0.9401$, $\mathrm{F}_{7,172}=402.5, P<0.01$; Table 7 ). A more complex model, which contained the same three-way interaction and the addition of moisture as a main effect, is the only other plausible model $(\triangle \mathrm{AICc}<2$; Table 7$)$.

The temperature sensitivity of day 1 respiration varied by vegetation type, depth and temperature, as captured by the top ranked three-way interaction (Table 8). At the shallow depth, average Q-10 was 0.5 units higher in graminoid soils than shrub soils (Q-10 mean (mean-1 s.e., mean +1 s.e.): shallow graminoid $=2.38 \quad(2.26,2.52)$, shallow shrub $=1.91(1.85,1.98))$. For soils in the deep depth increment, day 1 respiration Q-10 for shrub soils was slightly higher than graminoid soils (Q-10 mean (mean-1 s.e., mean +1 s.e.): shallow graminoid $=2.20$
(2.11, 2.29), shallow shrub $=2.54 \quad(2.41,2.67))$. The moisture effect that appears in the second ranked model indicates that temperature sensitivity of day 1 respiration rate decreases slightly at higher moistures $\left.\left(B_{\text {Moisture }} 60 \% \mathrm{WHC}\right)=-0.047 \pm 0.043, \mathrm{P}=0.29\right)$.

\section{Discussion}

In this paper, we measured the temperature and moisture effects on soil respiration and temperature sensitivity of decomposition for two tundra vegetation types. Mineral soil associated with graminoid-dominated vegetation had greater carbon storage, greater losses from decomposition, and a higher temperature sensitivity than shrub-dominated soils.

$\mathrm{CO}_{2}$ production rates calculated from cumulative respiration in the low temperature treatment (shrub= $501 \mu \mathrm{g} \mathrm{CO}_{2}-\mathrm{C} \mathrm{gOM}^{-1} \mathrm{~d}^{-1}$, graminoid $=741 \mu \mathrm{g} \mathrm{CO}_{2}-\mathrm{C}$ $\mathrm{gOM}^{-1} \mathrm{~d}^{-1}$ ) was within the range reported by previous incubation studies for Arctic soils at comparable temperature and duration, 52-967 $\mu \mathrm{g} \mathrm{CO}_{2}-\mathrm{C} \mathrm{gC^{-1 }} \mathrm{d}^{-1}$ [39-43]. Within these averages, we found shallow soils to have much higher $\mathrm{CO}_{2}$ production (shrub soils = $1,545 \mu \mathrm{g} \mathrm{CO}_{2}-\mathrm{C} \mathrm{gOM}^{-1} \mathrm{~d}^{-1}$, graminoid $=2,969 \mu \mathrm{g} \mathrm{CO}_{2}-\mathrm{C}$ $\mathrm{gOM}^{-1} \mathrm{~d}^{-1}$ ) than other reported values. The reasons for this divergent result are unclear, but suggest a highly available labile pool of mineralizable carbon in the upper mineral soil horizons. Deep soils, however, have $\mathrm{CO}_{2}$ production rates that are within the range of rates reported in other studies (shrub soils $=123 \mu \mathrm{g} \mathrm{CO}_{2}-\mathrm{C}$ gOM $^{-1} \mathrm{~d}^{-1}$, graminoid $=185 \mu \mathrm{g} \mathrm{CO}_{2}-\mathrm{C} \mathrm{gOM}^{-1} \mathrm{~d}^{-1}$ ).

\section{Vegetation and depth effects}

We hypothesized that vegetation type would affect respiration and temperature sensitivity of decomposition. We observed greater cumulative respiration in graminoid soils than in shrub soils (by nearly 1.8 times), which supports our hypothesis that graminoid soils, with lower $\mathrm{C}: \mathrm{N}$ ratios, would have greater carbon mineralization. Elberling et al. [44] also found differences in heterotrophic respiration from Dryas, Cassiope and Salix vegetated soils in northeast Greenland, but these differences were not associated with variation in $\mathrm{C}: \mathrm{N}$. Even when unrelated to stoichiometry, vegetation-based differences in soil respiration are important at the landscape scale. Other soil organic matter properties, such as the abundance of polysaccharides and proteins, are strongly

Table 5 Plausible models ( $\triangle \mathrm{AICC}$ ) explaining temperature sensitivity of decomposition (Q-10)

\begin{tabular}{|c|c|c|c|c|c|c|}
\hline ModelRank & Predictor Variables & No. of Param-eters & $\mathrm{AlCC}$ & $\Delta \mathrm{AICC}$ & AlCc Model Weight & Log-Likelihood \\
\hline 1 & Temp + Moisture + Veg + Depth + Moisture:Veg + Veg:Depth & 8 & -18.423 & 0 & 0.208 & 17.745 \\
\hline 2 & Temp + Veg + Depth+ Veg:Depth & 6 & -17.392 & 1.030 & 0.124 & 15.003 \\
\hline 3 & Temp + Moisture + Veg + Depth + Moisture:Veg & 7 & -16.427 & 1.996 & 0.077 & 15.625 \\
\hline
\end{tabular}

Models that contain all four main effects (temperature (Temp), vegetation type (Veg), moisture level (Moisture), depth (Depth)), a moisture-vegetation interaction (Moisture:Veg), and a vegetation-depth interaction (Veg:Depth) are preferred 
Table 6 Model summary from the top-ranked model of Q-10

\begin{tabular}{|c|c|c|c|c|c|}
\hline Parameter & Estimate & Std Error & $P$-value & $e^{\wedge}(B)$ & $\%$ effect $^{*}$ \\
\hline Intercept & 0.931 & 0.0657 & $<0.001$ & 2.537 & N/A \\
\hline Temp & -0.009 & 0.003 & 0.003 & 0.991 & -0.941 \\
\hline Moisture (60 \% WHC) & 0.112 & 0.052 & 0.031 & 1.119 & 11.894 \\
\hline Veg (Shrub) & -0.168 & 0.064 & 0.009 & 0.846 & -15.437 \\
\hline Depth (Deep) & -0.136 & 0.052 & 0.010 & 1.146 & 14.624 \\
\hline Moisture (60 \% WHC) : Veg (Shrub) & -0.152 & 0.073 & 0.039 & 0.859 & -14.113 \\
\hline Veg (Shrub) : Depth (Deep) & 0.149 & 0.074 & 0.045 & 1.160 & 16.046 \\
\hline
\end{tabular}

Parameter estimates, standard errors, $p$-values, back-transformed parameter estimates $\left(\mathrm{e}^{\wedge}(\mathrm{B})\right)$, and percent effect are reported for each model term

$*$ effect $=100^{*}\left(e^{\mathrm{B}}-1\right)$

related to $\mathrm{CO}_{2}$ mineralization [40]. Our results show that not only is the carbon pool larger in graminoid soils than in shrub soils [35], but $\mathrm{CO}_{2}$ mineralization potential is higher as well. This suggests that graminoid soils, which occupy a smaller fraction of our study area than shrubs, are nonetheless a "hot spot" for carbon storage and atmospheric exchange relative to shrub soils.

Vegetation type also had an effect on temperature sensitivity of decomposition, but the degree of difference varied between the two soil depths. Q-10 of cumulative respiration in shallow graminoid soils was 0.5 units higher than shrub soils at the same depth. Higher temperature sensitivity of shallow graminoid soils was also observed for day 1 soil respiration, providing additional evidence that the vegetation-based differences in

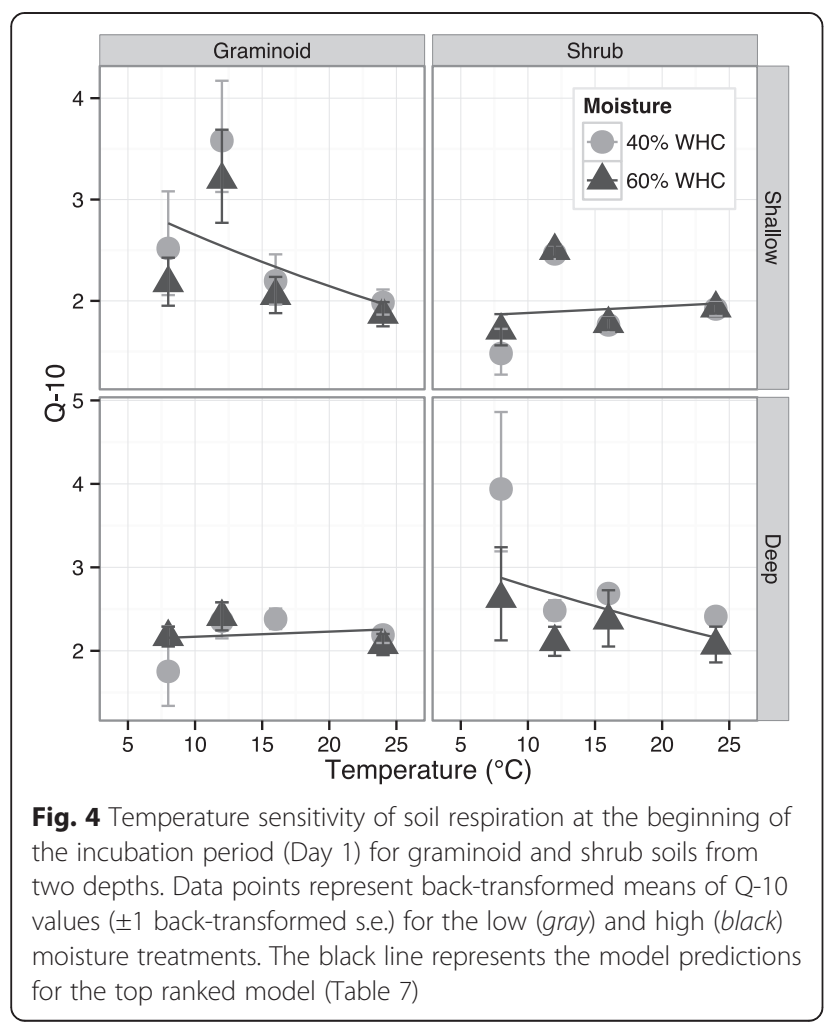

Q-10 are related to the temperature sensitivity of the full pool available for decomposition at the time of collection. The differences that we measure between vegetation types are small, especially considering that Q-10 values for both vegetation types are well below the average Q-10 of 3.4 for tundra soils [45]. However, because shallow graminoid soils have relatively high respiration rates, this difference in Q-10 has substantial implications for $\mathrm{CO}_{2}$ mineralization. For example, with a Q-10 of cumulative respiration set at 2.3 , an increase in graminoid soil temperature from 4 to $14{ }^{\circ} \mathrm{C}$ results in a respiration rate that is $1,480 \mu \mathrm{g} \mathrm{CO}_{2}-\mathrm{C} \mathrm{gOM}^{-1} \mathrm{~d}^{-1}$ (or $28 \%$ ) greater than if it is given the Q-10 of shrub soils, 1.8. These calculations suggest that the differences in temperature sensitivity of shallow soils between vegetation types are biologically meaningful and have implications for soil carbon mineralization.

Vegetation cover has the potential to mediate the effect of air warming on soil temperature [46] and indirectly influence the microbial response to climate change. We found shrub soils to be slightly cooler than graminoid soils during the growing season, which is possibly a result of canopy shading $[46,47]$. Thus, shrub expansion could reduce the effect of projected warming on soil temperature and microbial decomposition during the growing season. While shrubs soils were cooler in the summer, we observed equivalent annual mean soil temperature in the two vegetation types because shrub soils were warmer in the winter. Snow trapped in shrub vegetation can insulate and increase soil temperature relative to graminoid soils [48]. Further research is needed to determine the net outcome of the divergent mediators of soil temperature associated with shrub expansion. This research, coupled with our new understanding of differences in temperature sensitivity of decomposition and a spatially explicit model of the heterogeneous cover types found in west Greenland tundra, would be necessary to represent the landscapelevel response of decomposition to vegetation dynamics and atmospheric warming.

The difference in Q-10 between the two vegetation types in deep soils has a smaller effect on respiration 
Table 7 Plausible models ( $\triangle \mathrm{AICC}$ ) explaining temperature sensitivity of decomposition (Q-10) on day 1 of the incubation period

\begin{tabular}{|c|c|c|c|c|c|c|}
\hline ModelRank & Predictor Variables & No. of Parameters & $\mathrm{AlCC}$ & $\Delta \mathrm{AlCC}$ & AlCc Model Weight & Log-Likelihood \\
\hline 1 & $\begin{array}{l}\text { Temp + Veg + Depth +Depth:Temp + Veg: } \\
\text { Depth + Temp:Veg +Depth:Temp:Veg }\end{array}$ & 9 & 31.3 & 0 & 0.419 & -5.99 \\
\hline 2 & $\begin{array}{l}\text { Temp + Veg + Depth + MoistureDepth:Temp + Veg: } \\
\text { Depth + Temp:Veg + Veg:Depth:Temp }\end{array}$ & 10 & 32.4 & 1.09 & 0.243 & -5.38 \\
\hline
\end{tabular}

Models that contain all four main effects (temperature (Temp), vegetation type (Veg), moisture level (Moisture), depth (Depth)), a moisture-vegetation interaction (Moisture:Veg), and a vegetation-depth interaction (Veg:Depth) are preferred

when compared to shallow soils. If the temperature of deep graminoid soils (with Q-10 $=2.7$ ) increases from 4 to $14{ }^{\circ} \mathrm{C}$, the respiration rate would be only $55 \mu \mathrm{g} \mathrm{CO}-\mathrm{C}$ $\mathrm{gOM}^{-1} \mathrm{~d}^{-1}$ (or $13 \%$ ) greater than if the temperature sensitivity were equal to that of shrub soils $(\mathrm{Q}-10=2.3)$. While the Q-10 values of cumulative respiration in these deep soils are higher than the shallow soils, the respiration rates are lower, so the net effect of the 0.3 unit difference in $\mathrm{Q}-10$ between the soils is probably not biologically meaningful.

The shallow graminoid soils we studied have significantly lower C:N ratios than shallow shrub soils [35], so our finding that they are more temperature sensitive than shallow shrub soils does not support thermodynamic predictions that temperature sensitivity decreases with carbon quality. It is possible that the relationship between quality and temperature sensitivity is constrained by other soil factors and limitations, such as nitrogen availability. The shrub soils we studied have significantly smaller pools of nitrogen [35], and the availability of mineral nitrogen can limit rates of enzyme synthesis necessary for carbon mineralization [49]. It is also possible that $\mathrm{C}: \mathrm{N}$ is not indicative of carbon quality because it does not capture the influences of molecular structure or physical aggregation, which are two characteristics that can determine the biological availability of soil carbon [50,51].

In addition to chemical characteristics, physical protection of organic carbon through associations with mineral substrates is a plausible mechanistic control on

Table 8 Model summary from the top-ranked model of Q-10 on day 1

\begin{tabular}{lccc}
\hline Parameter & Estimate & Std Error & P-value \\
\hline Intercept & 1.187 & 0.125 & $<0.001$ \\
Temp & -0.021 & 0.008 & 0.007 \\
Veg (Shrub) & -0.590 & 0.168 & $<0.001$ \\
Depth (Deep) & -0.441 & 0.168 & 0.010 \\
Depth (Deep) : Temp & 0.024 & 0.010 & 0.023 \\
Veg (Shrub) : Temp & -0.025 & 0.010 & 0.019 \\
Veg (Shrub) : Depth (Deep) & 1.043 & 0.237 & 4.394 \\
Depth (Deep) : Temp : Veg (Shrub) & -0.045 & 0.015 & 0.003 \\
\hline
\end{tabular}

Parameter estimates, standard errors, p-values, back-transformed parameter estimates $\left(\mathrm{e}^{\wedge}(\mathrm{B})\right)$, and percent effect are reported for each model term $\%$ effect $=100^{*}\left(e^{\mathrm{B}}-1\right)$ the temperature sensitivity of organic matter decomposition in mineral soils [33]. Carbon that is more tightly bound to mineral surfaces is less accessible to microbial decomposition [28] and may be more temperature sensitive. Petrenko et al. [35] showed that the physical protection of the same shrub and graminoid soils analyzed in our study was generally similar, with the largest fraction of carbon (40-60 \%) weakly adsorbed to mineral surfaces. The single exception was the cation-bound $\mathrm{C}$ pool, which has an intermediate strength association with mineral substrate, and was significantly higher in shrub soils at the deeper 20-40 cm depth increment [35]. These findings show that the parent material provides a comparable mineral matrix for physical protection of carbon in the two vegetation types, but carbon stored in the cation-bound pool of deep shrub soils is slightly larger than graminoid soils.

Based on this characterization of physical protection by Petrenko et al. [35], the Carbon-Quality Temperature hypothesis would predict that temperature sensitivity of decomposition should be equivalent in shallow graminoid and shrub soils. We would also predict that deep shrub soils, with a larger cation-bound $\mathrm{C}$ pool, should be more temperature sensitive than deep graminoid soils. However, our direct measurement of temperature sensitivity revealed that graminoid soils have a higher temperature sensitivity than shrub soils, which suggests that physical protection does not explain differences in Q-10 that we observe between vegetation types. On the other hand, the vegetationdepth interaction term in our model of temperature sensitivity shows an increase in Q-10 for shrub soils with depth, which corresponds with the larger cation-bound pool. The cation pool size can be modified by vegetation through cation uptake rates or mineral substrate weathering, which increases cation availability [34]. The difference in physical protection between vegetation types may contribute to the variation in temperature sensitivity observed within the shrub soil profile. This interpretation suggests that physical protection is a control on Q-10 within the shrub soil profile, but not in the comparison of soil types. The different soil types may have dominant controls on temperature sensitivity, such as nutrient limitation, as previously discussed.

The differences in carbon mineralization, along with soil carbon content and $\mathrm{C}: \mathrm{N}$ ratios [35], between graminoid and shrub soils indicate that the vegetation classes 
in the study area have been persistent in their spatial distribution for sufficiently long to show meaningful differences in soil properties. A long-term field manipulation in the same tundra landscape as this study found that grazing from large herbivores, which are common in the area, stabilized vegetation from warming-induced shrub expansion [52]. Furthermore, the relatively low carbon mineralization rates observed in shrub soils were consistent with findings that microbial activity in Arctic shrub soils can be suppressed by nitrogen limitation [49]. In general, the distinct soil carbon properties of the two soil types support our assumption of long-lived stability in the extent of the vegetation types.

\section{Temperature effects}

Our third hypothesis was supported by observing elevated Q-10 values at the lowest temperature treatments and a decline in temperature sensitivity with an increase in temperature for all soils except shallow shrub soils. A similar negative relationship between Q-10 and temperature is widely observed $[45,53,54]$, including in other Arctic soils $[9,55,56]$. In east Greenland, Cassiope heath soils have a similar average temperature sensitivity for decomposition $\left(\mathrm{Q}-10_{0-25^{\circ} \mathrm{C}}=2.1\right)$, with higher values in the lower range of temperatures studied $\left(\mathrm{Q}-10_{0-10^{\circ} \mathrm{C}}=2.5\right)$ [57].

This negative relationship may be a result of substrate limitation because the soils are released from the catalytic enzyme limitation that occurs at $0{ }^{\circ} \mathrm{C}$ or below $[56,58]$. It is also possible that respiration rates adjust to different temperatures as a result of microbial "thermal adaptation". This evolutionary mechanism is driven by trade-offs between maintaining binding structures versus conformational flexibility of respiratory enzymes. The outcome is a decrease in respiration rate from organisms adapted to high temperatures and an increase in respiration for organism adapted to low temperatures [59]. However, Bradford et al. [59] did not detect thermal adaptation until at least 11 weeks of incubation, so we are not certain that a functional shift in microbial community composition could occur in this study, after a 7-week incubation.

It is also important to consider that high $\mathrm{CO}_{2}$ production rates at warmer temperature treatments result in larger soil carbon losses and more rapid depletion of the labile carbon pool compared to lower temperature treatments. As a result, the soil carbon substrate at the end of the incubation is more recalcitrant in warmer soils. This mismatch in carbon quality between temperature treatments at the end of the incubation period has implications for the temperature sensitivity of decomposition. Specifically, we would expect that the more recalcitrant substrate present in higher temperatures would increase the temperature sensitivity relative to the lower temperature soils. However, our results show the opposite relationship (temperature sensitivity decreasing at warmer temperatures), which suggests that altered quality of carbon substrate in the incubated soils did not change the direction of the temperature effect on the temperature sensitivity of decomposition.

These results also draw attention to the need for thermodynamic theory that does not assume constant Q-10 across temperatures, but rather accounts for the temperature dependence of Q-10 [60]. This pattern in temperature sensitivity implies that small increases in temperature at low temperatures can have disproportionately large effects on carbon mobilization. On the other hand, shallow shrub soils, which have a smaller $\mathrm{N}$ pool [35], appear to have a constant Q-10 across a range of temperatures. It is possible that these soils are nitrogen limited and have a constrained microbial response to temperature at lower temperatures.

\section{Moisture effects}

Soil moisture had a positive effect on cumulative respiration. Other studies have observed an increase in soil respiration with moisture additions [57, 61, 62]. However, the magnitude of the moisture effect on cumulative respiration in this study was small relative to the effect of vegetation type and depth. This comparison suggests that soils are more substrate limited than moisture limited in the $40 \%$ to $60 \%$ WHC range, which spans the field soil moisture content at the time of collection (late growing season) and somewhat wetter conditions under projected climate change. It is likely that soil moisture would have a larger effect in conditions close to desiccation or saturation [36]. In very dry conditions, enzymatic activity is limited by supply of dissolved organic carbon [63], and in very wet conditions, microbial respiration is limited by oxygen availability due to saturation of pore space $[36,57]$.

Surprisingly, we observed a different moisture effect on temperature sensitivity in the two vegetation types. Soil moisture had a positive effect on Q-10 of cumulative respiration from graminoid soils, but no effect on shrub soils. These results suggest that the temperature sensitivity of decomposition is influenced by moisture in graminoid soils. However, the range of moisture treatments did not alter shrub soil temperature sensitivity. For Q-10 of day 1 respiration rates, moisture did not appear in the top ranked model and had a small negative effect on temperature sensitivity, indicating that moisture has a weaker control on temperature sensitivity of the more labile soil carbon pool present at the beginning of the incubation. By comparison, the moisture effect on the Q-10 of cumulative respiration across the entire incubation most likely reflects the input from the recalcitrant pool that is a larger proportion of total substrate for $\mathrm{CO}_{2}$ production over 
the full incubation. We conclude that graminoid soils, which have a higher respiration potential and higher temperature sensitivity of decomposition, are expected to be even more responsive to warming under a climate scenario with increased precipitation as a result of the moisture effect on the temperature sensitivity of the recalcitrant carbon pool. In a synthesis of biogeochemical models, Sierra et al. show that temperature has a stronger control than moisture on apparent sensitivity of decomposition rates at intermediate moisture content, such as those used in our study [36]. Our finding that soil moisture has an effect on temperature sensitivity aligns well with field studies, which suggest that soil moisture is an important control of in-situ soil respiration and temperature sensitivity of soil decomposition [64-67]. It is possible, however, that increases in water inputs will not result in an corresponding increase in soil moisture, as was observed in a field manipulation in shrub tundra in northwest Greenland with well-drained soil and strong seasonal variation in moisture [68].

\section{Conclusions}

The results of this study show that soils associated with graminoid vegetation, which have a larger carbon pool and lower $\mathrm{C}: \mathrm{N}$, have higher soil respiration rates and a higher temperature sensitivity of decomposition compared to shrub soils. Our findings indicate that the large stocks of carbon stored in graminoid soils should be more susceptible to mineralization in a warming Arctic. This susceptibility results from a higher temperature sensitivity in the shallow mineral soil layer. Carbon stored in shrub soils was relatively less sensitive to warming. Any soil moisture increases consistent with climate model precipitation projections are expected to increase soil respiration in both vegetation types. Additionally, higher soil moisture should increase the temperature sensitivity of graminoid soils, but may have little to no effect on the temperature sensitivity of shrub soils. Shrub expansion into areas that are presently graminoid-dominated could lead to a reduction in soil carbon accumulation and a decrease in the temperature sensitivity of carbon mineralization, such that these soils would more closely resemble the carbon storage and temperature sensitivity of soil associated with current shrub vegetation. These results highlight the importance of the interactive effects of vegetation type, temperature, and moisture in determining the response of soil decomposition to climate change.

\section{Methods}

\section{Study site}

We conducted fieldwork in dwarf shrub tundra near Kangerlussuaq, Greenland $\left(67.103^{\circ} \mathrm{N}, 50.286^{\circ} \mathrm{W}\right)$, where mean annual temperature is $-5.7{ }^{\circ} \mathrm{C}$, mean growing season temperature is $9.2^{\circ} \mathrm{C}$. Estimates of annual precipitation in the area range from 140 to $252 \mathrm{~mm}[69,70]$, which classify it as a semi-arid ecosystem. The study site is located near the current extent of the Greenland ice sheet and was deglaciated approximately 7,000 years ago [71]. The location is proximate to terrestrial ecology research sites that were established in 2002 [4, 52].

We measured air temperature at $30-\mathrm{cm}$ above ground level every four hours from July 21, 2011 to July 20, 2012 using Thermocron iButton temperature loggers (Model DS 1921G, Embedded Data Systems ${ }^{\circ}$ ) contained within a PVC capsule secured to a steel rod, positioned under a roof cover to shade from direct insolation in a shrub-free location. We recorded soil temperature every four hours using iButtons buried at 5-cm depth within graminoid and shrub vegetation patches located within $300 \mathrm{~m}$ of the sampling area. Each iButton was wrapped in parafilm and neoprene plastic for waterproofing. We defined the growing season as the third week of May to the first week of August (5/22 - 8/7) to align with aboveground phenology [52, 72].

The field area consists of a heterogeneous patchwork of graminoid and shrub vegetation. We sampled from shrub patches that were dominated by Betula nana, which is a very common shrub in the area, along with Salix glauca, Vaccinium uliginosum, Rhododendron groenlandicum and Rhododendron lapponicum. Graminoid patches were dominated by Poa pratensis. Soils in this region are characterized as humus-poor arctic brown gelisols [73] with a thin organic horizon developed on loess substrate [74]. Observations from soil pits at a neighboring and comparable field site reveal that the organic horizon in the study area is 3-9 cm thick in graminoid and shrub vegetation (Bradley-Cook, unpublished data). At this same field site, depth of refusal measured with a t-bar, which is a proxy for depth of frozen ground, was at least $40 \mathrm{~cm}$ for both vegetation types, with a deeper active layer in shrub vegetation (shrub $=50.1 \pm 1.7 \mathrm{~cm}$, graminoid $=42.1 \pm 1.9 \mathrm{~cm}$; Bradley-Cook, unpublished data).

The study site was selected because it contained mixed shrub and graminoid vegetation cover, and was accessible from the road. We randomly selected five patches of each vegetation type that were approximately 2 meters in diameter and were separated by at least 10 meters. We sampled in the center of each patch to avoid possible shifting boundaries between the vegetation types. Accumulated litter corresponded dominant vegetation type, indicating that vegetation had persisted for at least many growing seasons. Furthermore, the carbon content of the soils collected differed between the two vegetation types [35], which supported our assumption that the vegetation boundaries are long-lived at this site. Topography can determine soil moisture, vegetation distribution 
and soil carbon accumulation [75]. For instance, physiological differences allow graminoid vegetation to occupy areas that are less well-drained. To minimize the effect of moisture and micro-topography, we avoided sampling in low-lying waterlogged areas and hummock formations.

Based on visual examination, we discarded the upper $3-9 \mathrm{~cm}$ of soil comprising the organic horizon, and then extracted the mineral soil beneath the organic horizon in $10 \mathrm{~cm}$ depth increments. We collected soil to a depth of at least $40 \mathrm{~cm}$ using a gas-powered auger (Earthquake $^{\text {ma }}$ 9800B) and $9.5 \mathrm{~cm}$ diameter drill bit and extension tube, as described by Petrenko and Friedland [76]. Within 24 hours of collection, we froze the samples to $-18{ }^{\circ} \mathrm{C}$ and later shipped them to the Biogeochemistry Laboratory at Dartmouth College, Hanover, NH, USA.

\section{Vegetation \& soil characteristics}

We conducted vegetation surveys within a $0.5-\mathrm{m}^{2}$ quadrat at the site of the soil core. We recorded species present, percent cover and canopy height as a proxy for biomass.

In the laboratory, we sieved samples to separate the 2$\mathrm{mm}$ size fraction and quantified organic matter content of each sample by measuring the loss-on-ignition (LOI) of approximately $10 \mathrm{~g}$ of oven dried soil after it was combusted at $450{ }^{\circ} \mathrm{C}$ for 5 hours. We use organic matter content (g OM g DM${ }^{-1}$ ) to standardize $\mathrm{CO}_{2}$ production measurements because LOI is measured on larger soil samples than is used in elemental analysis, and therefore better represents the carbon pool (including heterogeneous fine organic material) available for microbial decomposition in the incubation of $50 \mathrm{~g}$ soil samples. We measured percent carbon and nitrogen on approximately $6 \mathrm{mg}$ ground subsamples by combustion in a Carlo Erba NA 1500 elemental analyzer (Carlo Erba Instruments, Milan, Italy) using standard protocol [77] to determine $\mathrm{C}: \mathrm{N}$ ratios. We measured gravimetric soil water content by drying approximately $10 \mathrm{~g}$ of soil at $105^{\circ} \mathrm{C}$ and calculated mass loss over a percentage of dry soil. We also quantified $100 \%$ water holding capacity by saturating approximately $10 \mathrm{~g}$ of soil in a funnel lined with What$\operatorname{man}^{\circ} \# 40$ filter paper, and measured gravimetric soil water content after 24 hours of passive filtration. We calculated the percent WHC of field moist samples by dividing the soil water content by $100 \%$ WHC for each sample. We calculated the average LOI, gravimetric soil water content, $100 \% \mathrm{WHC}$, and percent WHC between the two shallow depth increments $(0-10 \mathrm{~cm}, 10-20 \mathrm{~cm})$ and the two deep depth increments $(20-30 \mathrm{~cm}, 30-40 \mathrm{~cm})$ for use in the laboratory incubations.

\section{Laboratory incubation experiment}

For soil collected from each core, we combined equal parts of paired $10 \mathrm{~cm}$ depth increments to create two broader depth categories: $0-20 \mathrm{~cm}$ and $20-40 \mathrm{~cm}$. Using these two aggregated soil depth increments, we conducted a 49-day laboratory incubation experiment to measure temperature and moisture sensitivity of decomposition. Soils were thawed at $4{ }^{\circ} \mathrm{C}$ for 6 days in advance of the incubation treatment. We sieved mineral soils to separate out the $2-\mathrm{mm}$ fraction. Some shallow samples had dense fine root structure that made sieving difficult. In these samples we removed roots larger than $1 \mathrm{~mm}$ in diameter and homogenized the samples by hand mixing. We incubated $50 \mathrm{~g}$ of fresh weight soil in half-pint ball jars at five temperatures $\left(4{ }^{\circ} \mathrm{C}, 8{ }^{\circ} \mathrm{C}, 12{ }^{\circ} \mathrm{C}, 16{ }^{\circ} \mathrm{C}, 25^{\circ} \mathrm{C}\right)$ and two moistures $(40 \%$ and $60 \%$ water holding capacity). The temperature levels were selected to represent a wide range of temperatures, which captured the mean growing season soil temperature at the low end of the range, regional warming scenarios at the intermediate levels [37], and a total range of $20^{\circ} \mathrm{C}$. The lowest moisture treatment was the average gravimetric soil moisture content of collected soil samples, and the high moisture treatment captured the direction and general magnitude of projected regional increases in precipitation with climate change (30-40 \% increase in western Greenland by 2051-2080 [37]). These treatment levels capture the general trend of precipitation increase, not modified by factors that might alter the modeled increase (e.g. evapotranspiration, seasonal variation). We assume that soil moisture increases from precipitation would probably exceed any decreases in soil moisture. To determine the target water content of the two moisture treatment levels, we multiplied the water mass within $100 \%$ WHC by 0.4 and 0.6 for each sample. We adjusted the water content of field moist samples by spraying additional water, or letting the soils dry at incubation temperature to target moisture. A shallow graminoid and a deep shrub sample were not included in the incubation because they did not contain enough soil to distribute among all experimental treatments. As a result, sample size varied by soil type (graminoid surface $(n=4)$, shrub surface $(n=5)$, graminoid deep $(n=5)$, shrub deep $(n=4))$. We weighed the jars every 2-3 days to monitor soil moisture throughout the incubation period and applied additional water with a spray bottle to maintain the target moisture level.

Carbon dioxide production rate was quantified seven times during the incubation period (day $1,4,7,14,28,49$ ). The first measurement began approximately 6 hours after soils were placed in incubators. Prior to each sampling, we flushed the jar headspace with compressed $\mathrm{CO}_{2}$-free air and sealed the jar for a 24-hour incubation period. After the incubation period, we collected a $10-\mathrm{mL}$ gas sample from the jar headspace, on which we measured $\mathrm{CO}_{2}$ concentration by injecting the gas into a LiCor- 8100 infrared gas analyzer via a trace gas extension valve (LiCor products, Lincoln, NE). We measured the headspace volume 
for each sample using a dilution function [78] as described in Bradley-Cook and Virginia [79] in order to calculate $\mathrm{CO}_{2}$ production from headspace concentration.

\section{Data analysis}

We compared canopy height between vegetation types using a two-sided t-test. We evaluated the effect of vegetation on gravimetric soil moisture content, $100 \%$ WHC, and percent WHC of field moist soils by using a mixed-effects model comparison approach. The full model contained vegetation type as the fixed effects, and soil depth nested within each core as a random effect. For each response variable, we used $\triangle \mathrm{AICc}$ to compare the full model to a null model with an intercept and the random effect.

To compare $\mathrm{CO}_{2}$ production between soil type and treatment, we calculated cumulative $\mathrm{CO}_{2}$ production over the incubation period by multiplying the average $\mathrm{CO}_{2}$ production of neighboring sample dates by the time interval that they captured, and summing these values for the incubation period.

Temperature sensitivity was characterized as Q-10, as defined by:

$$
Q_{10}=\left(\frac{R_{i}}{R_{4 \mathrm{C}}}\right)^{\frac{10}{T_{\mathrm{i}}-4}}
$$

where $R_{i}$ is cumulative $\mathrm{CO}_{2}$ production $\left(\mu \mathrm{g} \mathrm{C} \mathrm{g} \mathrm{OM}^{-1}\right.$ day ${ }^{-1}$ ) for a temperature level $T_{i}\left({ }^{\circ} \mathrm{C}\right)$ and $\mathrm{R}_{4^{\circ}} \mathrm{C}$ is the cumulative decomposition at the $4{ }^{\circ} \mathrm{C}$ base temperature ( $\mu \mathrm{g} \mathrm{C} \mathrm{g} \mathrm{OM}^{-1}$ day $^{-1}$ ) [80]. We also calculated Q-10 for the first measurement of $\mathrm{CO}_{2}$ production rates (day 1 ) to determine temperature sensitivity of the carbon pool that most closely resembles the substrate found in the soils at the time of collection.

We used an information-theoretic model comparison approach to test the effect of vegetation type, temperature, moisture and depth on temperature sensitivity (Q-10) for cumulative and day 1 respiration. The set of candidate models included all possible combinations of the four variables and their interactions and an intercept model, for a total of 65 models. We evaluated the fit of each model to the data using the second-order Akaike's information criteria (AICc). Models were ranked according to $\triangle \mathrm{AICc}$ values and were considered to be plausible if $\triangle \mathrm{AICc}$ was below 2 . For each model, $i$, in a set of candidate models, $r$, we calculated a model weight as:

$$
\mathrm{w}_{\mathrm{i}}=\frac{\mathrm{e}^{-0.5 * \Delta \mathrm{AICc}_{\mathrm{i}}}}{\sum_{\mathrm{r}=1}^{\mathrm{R}} \mathrm{e}^{-0.5 * \Delta \mathrm{AICc}_{\mathrm{r}}}}
$$

Model weights, which sum to 1 across the candidate set, describe the weight of evidence in favor of a given model being the best in the candidate set [81]. Model selection analysis was performed with the AICcmodavg package in $\mathrm{R}$ [82]. Model comparisons for cumulative respiration and Q-10 produced a subset of 3 competing models that fit the data almost equally well. All plausible models of cumulative respiration included a number of conserved terms. Many of the plausible models also contained additional terms that had limited explanatory power, as evidenced by little to no change in the loglikelihood of the model relative to a more parsimonious model. These variables did not improve model fit, but were included in highly ranked models because they were associated with a good model and only incurred a small penalty. This type of model term has been labeled "pretending variable" [38] and we ignored them in our interpretations. We identified all models, but focused our analysis on the core main effects and interaction terms that were conserved across all reasonably plausible models. The set of plausible models for the prediction of Q-10 were also nested, but the most complex model did not contain any pretending variables. In this case, we focused our interpretation on this most complex model. Model terms were evaluated based on effect size and standard error around the parameter estimate. We did not conduct model averaging primarily because our objective was to test hypotheses about the effects on the response variables. In addition, there are no clear guidelines on how to handle nested models in a model averaging approach [83]. We did examine parameter estimates in all plausible models (Additional file 3: Table S1 and Additional file 4: Table S2) to ensure that there were no big differences from the focal model.

One graminoid surface sample was identified as an outlier because the cumulative respiration was beyond 1.5 times the interquartile range. We compared linear model results with and without the outlier included to confirm that the exclusion of this sample led to a more conservative comparison between vegetation types and depths. Cumulative respiration data and Q-10 values were log-transformed to meet normal distribution assumptions. Log-transformed means and standard errors were back-transformed to report biologically meaningful descriptive statistics. Prior to conducting all t-tests, we tested the assumption of homogeneity of variances using F-test. Significance was determined at $\alpha=0.05$. Analyses were conducted in $\mathrm{R}$ version 3.0.2 [84] along with the plyr [85], and reshape [86] packages. Graphs were produced using the ggplot2 package in $\mathrm{R}$ [87].

\section{Additional files}

Additional file 1: Figure S1. Cumulative Respiration of shrub and graminoid soils with outliers at two depths under experimental treatments. Large points mark back-transformed averages of the low 
moisture (gray circles) and high moisture (black triangles) treatment, and error bars show back-transformed 1 standard error around the mean. Small data points mark individual samples within each treatment, including the graminoid outlier (asterisks). (EPS $133 \mathrm{~kb}$ )

Additional file 2: Figure S2. Q-10 of shrub and graminoid soils with outliers at two depths under experimental treatments. Large points represent back-transformed averages of the low moisture (gray circles) and high moisture (black triangles) treatment, and error bars show backtransformed 1 standard error around the mean. Small data points represent individual samples within each treatment, including the graminoid outlier (asterisks). (EPS $107 \mathrm{~kb}$ )

Additional file 3: Table S1. Model parameters for all plausible models of cumulative respiration, where $Y$ is $\log$ (cumulative respiration), including back-transformed estimate $\left(\mathrm{e}^{\wedge}(\mathrm{B})\right)$. (DOC $\left.41 \mathrm{~kb}\right)$

Additional file 4: Table S2. Model parameters for all plausible models of temperature sensitivity (Q-10), including back-transformed estimate $\left(\mathrm{e}^{\wedge}(\mathrm{B})\right) .(\mathrm{DOC} 40 \mathrm{~kb})$

\section{Abbreviations}

C: Carbon; $\mathrm{CO}_{2}$ : Carbon dioxide; OM: Organic matter; WHC: Water Holding Capacity.

\section{Competing interests}

The authors declare that they have no competing interests.

\section{Authors' contributions}

JBC conceived of and designed the study, collected soil samples and field data, carried out the incubation experiment, conducted data analysis and drafted manuscript. CP conceived of and designed the study, collected soil samples and field data, participated in incubation data collection, and provided critical revisions of the manuscript. AF provided critical revisions to the manuscript. RV conceived of study, contributed to data interpretation, and provided critical revisions to the manuscript. All authors read and approved the final manuscript.

\section{Acknowledgements}

This work was made possible by funding from the NSF IGERT Polar Environmental Change award 0801490 and support from the Institute of Arctic Studies within the Dickey Center for International Understanding. We are grateful to Courtney Hammond Wagner, Alexandra Giese, Jessica Trout-Haney, Lee Corbett, and Stephanie Gregory for zealous assistance in the field, Angela Spickard for contributions to the laboratory incubation, Tom Kraft and Lauren Culler for statistics assistance, Paul Zietz for laboratory support, and Lee McDavid for administrative support. Matt Ayres provided valuable mentorship and access to incubators. We thank Dartmouth's Ecology \& Evolutionary Biology Graduate Program and the Environmental Studies Program for administrative support and access to research facilities.

\section{Author details}

'Department of Biological Sciences, Dartmouth College, Hanover NH 03755 , USA. ${ }^{2}$ Environmental Studies Program, Dartmouth College, Hanover NH 03755, USA. ${ }^{3}$ Environmental Studies Program and Institute of Arctic Studies, Dartmouth College, Hanover NH 03755, USA.

\section{Received: 31 July 2015 Accepted: 6 February 2016}

Published online: 12 March 2016

\section{References}

1. Urban M, Forkel M, Eberle J, Huettich C, Schmullius C, Herold M. Pan-arctic climate and land cover trends derived from multi-variate and multi-scale analyses (1981-2012). Remote Sensing. 2014;6:2296-316.

2. Myers-Smith $1 \mathrm{H}$, Elmendorf SC, Beck PSA, Wilmking M, Hallinger M, Blok D, Tape KD, Rayback SA, Macias-Fauria M, Forbes BC, Speed JDM, BoulangerLapointe N, Rixen C, Levesque E, Schmidt NM, Baittinger C, Trant AJ, Hermanutz L, Collier LS, Dawes MA, Lantz TC, Weijers S, Jørgensen RH, Buchwal A, Buras A, Naito AT, Ravolainen V, Schaepman-Strub G, Wheeler JA, Wipf S, Guay KC, Hik DS, Vellend M. Climate sensitivity of shrub growth across the tundra biome. Nature Climate Change. 2015; doi:10.1038/nclimate2697.

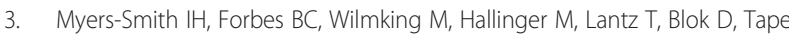
KD, Macias-Fauria M, Sass-Klaassen U, Levesque E, Boudreau S, Ropars P. Hermanutz L, Trant A, Collier LS, Weijers S, Rozema J, Rayback SA, Schmidt NM, Schaepman-Strub G, Wipf S, Rixen C, Menard CB, Venn S, Goetz S, Andreu-Hayles L, Elmendorf S, Ravolainen V, Welker J, Grogan P, Epstein HE, Hik DS. Shrub expansion in tundra ecosystems: dynamics, impacts and research priorities. Environ Res Lett. 2011;6:045509.

4. Cahoon SMP, Sullivan PF, Shaver GR, Welker JM, Post E. Interactions among shrub cover and the soil microclimate may determine future Arctic carbon budgets. Ecol Lett. 2012;15:1415-22.

5. Tarnocai C, Canadell JG, Schuur EAG, Kuhry P, Mazhitova G, Zimov S. Soil organic carbon pools in the northern circumpolar permafrost region. Global Biogeochem Cy. 2009;23, GB2023.

6. Hugelius G, Strauss J, Zubrzycki S, Harden JW, Schuur EAG, Ping CL,Schirrmeister L, Grosse G, Michaelson GJ, Koven CD, O'Donnell JA, Elberling B, Mishra U, Camill P, Yu Z, Palmtag J, Kuhry P. Estimated stocks of circumpolar permafrost carbon with quantified uncertainty ranges and identified data gaps. Biogeosciences. 2014;11:6573-93.

7. Schuur EAG, Mcguire AD, Schädel C, Grosse G, Harden JW, Hayes DJ, Hugelius G, Koven CD, Kuhry P, Lawrence DM, Natali SM, Olefeldt D, Romanovsky VE, Schaefer K, Turetsky MR, Treat CC, Vonk JE. Climate change and the permafrost carbon feedback. Nature. 2015;520:171-9.

8. McGuire AD, Anderson LG, Christensen TR, Dallimore S, Guo L, Hayes DJ, Heimann M, Lorenson TD, Macdonald RW, Roulet N. Sensitivity of the carbon cycle in the Arctic to climate change. Ecol Monogr. 2009;79:523-55.

9. Hollesen J, Elberling B, Jansson PE. Future active layer dynamics and carbon dioxide production from thawing permafrost layers in Northeast Greenland. Global Change Biol. 2011;17:911-26.

10. Schaefer $K$, Zhang T, Bruhwiler L, Barrett AP. Amount and timing of permafrost carbon release in response to climate warming. Tellus B. 2011;63:165-80.

11. Creamer CA, Filley TR, Boutton TW, Oleynik S, Kantola IB. Controls on soil carbon accumulation during woody plant encroachment: Evidence from physical fractionation, soil respiration, and delta- $13 \mathrm{C}$ of respired $\mathrm{CO} 2$. Soil Biol Biochem. 2011;43:1678-87.

12. Ostle NJ, Smith P, Fisher R, Woodward FI, Fisher JB, Smith JU, Galbraith D, Levy P, Meir P, McNamara NP, Bardgett RD. Integrating plant-soil interactions into global carbon cycle models. J Ecology. 2009;97:851-63.

13. Hollingsworth TN, Schuur EAG, Chapin III FS, Walker MD. Plant community composition as a predictor of regional soil carbon storage in Alaskan Boreal Black Spruce Ecosystems. Ecosystems. 2008;11:629-42.

14. Hooper D, Vitousek P. The effects of plant composition and diversity on ecosystem processes. Science. 1997;277:1302-5.

15. Chapin F, Bret-Harte M, Hobbie S. Plant functional types as predictors of transient responses of arctic vegetation to global change. J Veg Sci. 1996;7:347-58.

16. Haddix ML, Plante AF, Conant RT, Six J, Steinweg JM, Magrini-Bair K, Drijber RA, Morris SJ, Paul EA. The role of soil characteristics on temperature sensitivity of soil organic matter. Soil Sci Soc Am J. 2011;75:56-68.

17. Thomsen IK, Petersen BM, Bruun S, Jensen LS, Christensen BT. Estimating soil C loss potentials from the C to N ratio. Soil Biol Biochem. 2008;40:849-52.

18. Hobbie S. Temperature and plant species control over litter decomposition in Alaskan tundra. Ecol Monogr. 1996;66:503-22.

19. Jobbágy EG, Jackson RB. The vertical distribution of soil organic carbon and its relation to climate and vegetation. Ecol App. 2000;10:423-36.

20. Shaver GR, Billings WD. Root Production and Root Turnover in a Wet Tundra Ecosystem, Barrow, Alaska. Ecology. 1975;56:401-9.

21. Fontaine S, Barot S, Barré P, Bdioui N, Mary B, Rumpel C. Stability of organic carbon in deep soil layers controlled by fresh carbon supply. Nature. 2007;450:277-80.

22. Kuzyakov Y, Friedel JK, Stahr K. Review of mechanisms and quantification of priming effects. Soil Biol Biochem. 2000;32:1485-98.

23. Hudson JMG, Henry GHR, Cornwell WK. Taller and larger: shifts in Arctic tundra leaf traits after 16 years of experimental warming. Global Change Biol. 2011;17:1013-21.

24. Bosatta E, Ågren G. Soil organic matter quality interpreted thermodynamically. Soil Biol Biochem. 1999;31:1889-91.

25. von Lützow M, Kögel-Knabner I. Temperature sensitivity of soil organic matter decomposition—what do we know? Biol Fertil Soils. 2009;46:1-15.

26. Conant RT, Ryan MG, Ågren GI, Birge HE, Davidson EA, Eliasson PE, Evans SE, Frey SD, Giardina CP, Hopkins FM, Hyvönen R, Kirschbaum MUF, Lavallee 
JM, Leifeld J, Parton WJ, Megan Steinweg J, Wallenstein MD, Martin Wetterstedt J $\AA$, Bradford MA. Temperature and soil organic matter decomposition rates - synthesis of current knowledge and a way forward. Global Change Biol. 2011;17:3392-404.

27. Davidson EA, Janssens IA. Temperature sensitivity of soil carbon decomposition and feedbacks to climate change. Nature. 2006;440:165-73.

28. Tang J, Riley WJ. Weaker soil carbon-climate feedbacks resulting from microbial and abiotic interactions. Nature Climate Change. 2014. doi:10.1038/nclimate2438.

29. Hinzman LD, Deal CJ, McGuire AD, Mernild SH, Polyakov IV, Walsh JE. Trajectory of the Arctic as an integrated system. Ecological Applications. 2013;23:1837-68

30. Horwath JL, Sletten RS, Hagedorn B, Hallet B. Spatial and temporal distribution of soil organic carbon in nonsorted striped patterned ground of the High Arctic. J Geophys Res-Biogeo. 2008;113:G03S07.

31. Rumpel C, Koegel-Knabner I. Deep soil organic matter-a key but poorly understood component of terrestrial C cycle. Plant Soil. 2011;338:143-58.

32. Hugelius G, Kuhry P. Landscape partitioning and environmental gradient analyses of soil organic carbon in a permafrost environment. Global Biogeochemical Cycles. 2009;23, GB3006.

33. Dungait JAJ, Hopkins DW, Gregory AS, Whitmore AP. Soil organic matter turnover is governed by accessibility not recalcitrance. Global Change Biol. 2012;18:1781-96.

34. Kögel-Knabner I, Ekschmitt K, Flessa H, Guggenberger G, Matzner E, Marschner B, Lützow von M. An integrative approach of organic matter stabilization in temperate soils: Linking chemistry, physics, and biology. J Plant Nutrition and Soil Sci. 2008;171:5-13.

35. Petrenko CL, Bradley-Cook J, Lacroix E, Friedland AJ, Virginia RA. Mineral soil carbon and nitrogen storage in graminoid- and shrub-domintated soils of western Greenland. Arctic Science. In review.

36. Sierra CA, Trumbore SE, Davidson EA, Vicca S, Janssens I. Sensitivity of decomposition rates of soil organic matter with respect to simultaneous changes in temperature and moisture. J Adv Model Earth Syst. 2015;7:335-56.

37. Stendel M, Christensen JH, Aoalgeirsdottir G, Kliem N, Drews M. Regional climate change for Greenland and surrounding seas. Danish Meteorological Institute. 2007. http://978-87-7478-547-7. Accessed 15 Mar 2015

38. Anderson DR. Information Theory and Entropy. Model Based Inference in the Life Sciences: A Primer on Evidence. New York: Springer; 2008. p. 51-82.

39. Schädel C, Schuur EAG, Bracho R, Elberling B, Knoblauch C, Lee H, Luo Y, Shaver GR, Turetsky MR. Circumpolar assessment of permafrost $C$ quality and its vulnerability over time using long-term incubation data. Global Change Biol. 2014;20:641-52.

40. Treat CC, Wollheim WM, Varner RK, Grandy AS, Talbot J, Frolking S. Temperature and peat type control $\mathrm{CO} 2$ and $\mathrm{CH} 4$ production in Alaskan permafrost peats. Global Change Biol. 2014;20:2674-86.

41. Lee $H$, Schuur EA, Inglett KS, Lavoie M, Chanton JP. The rate of permafrost carbon release under aerobic and anaerobic conditions and its potential effects on climate. Global Change Biol. 2012;18:515-27.

42. Hobbie S, Nadelhoffer K. A synthesis: the role of nutrients as constraints on carbon balances in boreal and arctic regions. Plant Soil. 2002;242:163-70

43. Mikan C, Schimel J, Doyle A. Temperature controls of microbial respiration in arctic tundra soils above and below freezing. Soil Biol Biochem. 2002;34:1785-95.

44. Elberling B, Jakobsen BH, Berg P, Søndergaard J, Sigsgaard C. Influence of vegetation, temperature, and water content on soil carbon distribution and mineralization in four high arctic soils. Arct Antarct Alp Res. 2004;36:528-38.

45. Hamdi S, Moyano F, Sall S, Bernoux M, Chevallier T. Synthesis analysis of the temperature sensitivity of soil respiration from laboratory studies in relation to incubation methods and soil conditions. Soil Biol Biochem. 2013;58:115-26.

46. Blok D, Heijmans MMPD, Schaepman-Strub G, Kononov AV, Maximov TC Berendse F. Shrub expansion may reduce summer permafrost thaw in Siberian tundra. Global Change Biol. 2010;16:1296-305

47. Yi S, Woo M, Arain MA. Impacts of peat and vegetation on permafrost degradation under climate warming. Geophys Res Lett. 2007;34, L16504.

48. Sturm M, Holmgren J, McFadden J. Snow-shrub interactions in Arctic tundra: A hypothesis with climatic implications. J Climate. 2001;14:336-44.

49. Sistla SA, Asao S, Schimel JP. Detecting microbial N-limitation in tussock tundra soil: Implications for Arctic soil organic carbon cycling. Soil Biol Biochem. 2012;55:78-84.

50. Giblin A, Nadelhoffer KJ, Shaver G, Laundre JA, McKerrow AJ. Biogeochemical diversity along a riverside Toposequence in Arctic Alaska. Ecol Monogr. 1991;61:415.
51. Weintraub MN, Schimel JP. Interactions between carbon and nitrogen mineralization and soil organic matter chemistry in arctic tundra soils. Ecosystems. 2003;6:129-43.

52. Post E, Pedersen C. Opposing plant community responses to warming with and without herbivores. P Natl Acad Sciences. 2008;105:12353-8.

53. Del Grosso SJ, Parton WJ, Mosier AR, Holland EA, Pendall E, Schimel DS, Ojima DS. Modeling soil CO2 emissions from ecosystems. Biogeochemistry. 2005;73:71-91.

54. Kirschbaum M. The temperature dependence of soil organic matter decomposition, and the effect of global warming on soil organic C storage. Soil Biol Biochem. 1995.

55. Hobbie S, Miley T, Weiss M. Carbon and nitrogen cycling in soils from acidic and nonacidic tundra with different glacial histories in Northern Alaska. Ecosystems. 2002;5:761-74.

56. Karhu K, Fritze H, Tuomi M, Vanhala P, Spetz P, Kitunen V, Liski J. Temperature sensitivity of organic matter decomposition in two boreal forest soil profiles. Soil Biol Biochem. 2010;42:72-82.

57. Elberling B. Seasonal trends of soil CO2 dynamics in a soil subject to freezing. J Hydrology. 2003.

58. Atkin $\mathrm{O}$. Thermal acclimation and the dynamic response of plant respiration to temperature. Trends in Plant Sci. 2003;8:343-51.

59. Bradford MA, Watts BW, Davies CA. Thermal adaptation of heterotrophic soil respiration in laboratory microcosms. Global Change Biol. 2010;16:1576-88.

60. Schipper LA, Hobbs JK, Rutledge S, Arcus VL. Thermodynamic theory explains the temperature optima of soil microbial processes and high Q10 values at low temperatures. Global Change Biol. 2014;20:3578-86.

61. Howard DM, Howard P. Relationships between CO2 evolution, moisture content and temperature for a range of soil types. Soil Biol Biochem. 1993;25:1537-46.

62. Lomander A, Kätterer T, Andrén O. Carbon dioxide evolution from top- and subsoil as affected by moisture and constant and fluctuating temperature. Soil Biol Biochem. 1998:30:2017-22

63. Lellei-Kovács E, Kovács-Láng E, Botta-Dukát Z, Kalapos T, Emmett B, Beier C. Thresholds and interactive effects of soil moisture on the temperature response of soil respiration. European J Soil Biol. 2011;47:247-55.

64. Natali SM, Schuur E, Mauritz M. Permafrost thaw and soil moisture driving CO2 and $\mathrm{CH} 4$ release from upland tundra. J Geophys Res-Biogeo. 2015;120:525-37.

65. Briones MJI, McNamara NP, Poskitt J, Crow SE, Ostle NJ. Interactive biotic and abiotic regulators of soil carbon cycling: evidence from controlled climate experiments on peatland and boreal soils. Global Change Biol. 2014;20:2971-82

66. Nobrega S, Grogan P. Deeper snow enhances winter respiration from both plant-associated and bulk soil carbon pools in birch hummock tundra. Ecosystems. 2007;10:419-31.

67. Illeris L, Christensen TR, Mastepanov M. Moisture Effects on Temperature Sensitivity of $\mathrm{CO} 2$ Exchange in a Subarctic Heath Ecosystem. Biogeochemistry. 2004;70:315-30.

68. Sullivan PF, Welker JM, Steltzer H, Sletten RS, Hagedorn B, Arens SJT, Horwath $J$ L. Energy and water additions give rise to simple responses in plant canopy and soil microclimates of a high arctic ecosystem. J Geophys Res-Biogeo. 2008;113:G03S08.

69. NOAA. Sondre Stromfjord. ftp://ftp.atdd.noaa.gov/pub/GCOS/WMONormals/TABLES/REG_VI/GL/04231.TXT. Accessed 24 Jun 2015.

70. Mernild SH, Hanna E, McConnell JR, Sigl M, Beckerman AP, Yde JC, Cappelen J, Malmros JK, Steffen K. Greenland precipitation trends in a longterm instrumental climate context (1890-2012): evaluation of coastal and ice core records. Int J Climatol. 2014;35:303-20.

71. Levy LB, Kelly MA, Howley JA, Virginia RA. Age of the Orkendalen moraines, Kangerlussuaq, Greenland: constraints on the extent of the southwestern margin of the Greenland Ice Sheet during the Holocene. Quaternary Science Rev. 2012;52:1-5.

72. Post E, Forchhammer MC. Climate change reduces reproductive success of an Arctic herbivore through trophic mismatch. Philos T R Soc B. 2008;363:2367-73.

73. Jones A, Stolbovoy V, Tarnocai C, Broll G, Spaargaren O, Montarella L, editors. In: Soil Atlas of the Northern Circumpolar Region. Luxembourg: European Commission, Office for Official Publications of the European Communities; 2009

74. Heindel RC, Chipman JW, Virginia RA. The Spatial Distribution and Ecologica Impacts of Aeolian Soil Erosion in Kangerlussuaq, West Greenland. Ann Assoc Am Geographers. 2015;105:875-90.

75. Sullivan PF, Arens SJT, Chimner RA, Welker JM. Temperature and microtopography interact to control carbon cycling in a high arctic fen. Ecosystems. 2008;11:61-76. 
76. Petrenko CL, Friedland AJ: Mineral Soil Carbon Pool Responses to Forest Clearing in Northeastern Hardwood Forests. GCB Bioenergy 2014; doi:10.1111/gcbb.12221

77. Sollins P, Glassman C, Paul EA, Swanston C, Lajtha K, Heil JW. C and N Dry Combustion. In: Robertson GP, Coleman DC, Bledsoe C, Sollins P, editors. Standard Soil Methods for Long-Term Ecological Research. New York: Oxford; 1999. p. 92-95

78. Curiel Yuste J, Baldocchi DD, Gershenson A, Goldstein A, Misson L, Wong S. Microbial soil respiration and its dependency on carbon inputs, soil temperature and moisture. Global Change Biol. 2007;13:2018-35.

79. Bradley-Cook J, Virginia RA: Soil carbon storage, respiration potential, and quality across an age and climate gradient, western Greenland. Polar Biol. 2016; doi:10.1007/s00300-015-1853-2

80. Leifeld J, Fuhrer J. The temperature response of $\mathrm{CO} 2$ production from bulk soils and soil fractions is related to soil organic matter quality. Biogeochemistry. 2005;75:433-53.

81. Burnham KP, Anderson DR. Model Selection and Multimodel Inference: A Practical Information-Theoretic Approach. New York: Springer; 2002.

82. Mozerolle MJ. AlCcmodavg: Model selection and multimodel inference based on (Q)AIC(C), 2nd ed. R package; 2015. http://CRAN.R-project.org/ package $=$ AlC $c$ modavg

83. Grueber CE, Nakagawa S, Laws R, Jamieson IG. Multimodel inference in ecology and evolution: challenges and solutions. J Evolutionary Biol. 2011;24:699-711.

84. Team RC. R: A language and environment for statistical computing. Vienna, Austria: R Foundation for Statistical Computing. http://www.R-project.org/.

85. Wickham H. The Split-Apply-Combine Strategy for Data Analysis. J Statistical Software. http://www.jstatsoft.org/v40/i01/. 2011;40:1-29.

86. Wickham H. Reshaping data with the reshape package. Journal of Statistical Software. http://www.jstatsoft.org/v21/i12/paper. 2007;21.

87. Wickham H. ggplot2: Elegant graphics for data analysis. New York: Springer; 2009

\section{Submit your next manuscript to BioMed Central and we will help you at every step:}

- We accept pre-submission inquiries

- Our selector tool helps you to find the most relevant journal

- We provide round the clock customer support

- Convenient online submission

- Thorough peer review

- Inclusion in PubMed and all major indexing services

- Maximum visibility for your research

Submit your manuscript at www.biomedcentral.com/submit
Biomed Central 